\title{
EDITORIAL
}

\section{O PPGENF-UFRGS NO COMPASSO DOS AVANÇOS DA PÓS-GRADUAÇÃO EM ENFERMAGEM}

Os resultados da última avaliação trienal da Capes (2007-2009) demarcam um importante avanço da enfer magem no âmbito da pós-graduação strictu sensu e, nesse compasso, o Programa de Pós-G raduação da E scola de Enfermagem da U niversidade Federal do Rio G rande do Sul (PPGENF-UFRGS) comemora seu particular desempenho com a obtenção de nota 5, nesse sistema de avaliação.

Com M estrado desde 1998 e D outorado desde 2006, o PPGEN F -U F RG S foi precursor no E stado do Rio Grande do Sul e tem contribuído para o fortalecimento da pós-graduação em enfermagem na região sul e para formação de massa crítica que, gradativamente, extrapola fronteiras, na medida em que seus egressos vêm ocupando espaços profissionais estratégicos, em distintas localidades do país, com repercussões no ensino, pesquisa e assistência. A ssim, 0 Programa mobiliza-se em cumprir o importante quesito de relevância e progressiva inserção social, ciente do compromisso de per severar na busca da excelência acadêmica que se reverta em benefício de práticas qualificadas, nos mais diver sos campos da atuação profissional.

A conquista da nota 5 demonstra uma trajetória consolidada e, neste momento de congratulações, faz-se mister destacar a abertura de caminhos pelas gestões anterior es e o engajamento de todos que já participaram e/ ou participam do PPGE NF-UFRG S - docentes, discentes e corpo técnico-administrativo. A diciona-se o reconhecimento de que conquistas efetivas e promissoras resultam do empenho e dedicação de cada um, mas, sobretudo, da articulação coletiva, em meios às similitudes e diferenças, atributos igual mente importantes e que precisam ser valorizados quando se pensa em qualidade e se pretende avançar cada vez mais na construção do conhecimento, rumo a excelência.

\footnotetext{
a Coordenadora do Programa de Pós-Graduação da Escola de Enfermagem da Universidade Federal do Rio Grande do Sul (PPGENFUFRGS), Porto Alegre, Rio Grande do Sul, Brasil.
} 